\title{
Die Eroberung Thessalonikes durch die Sarazenen im Jahre 904.
}

Es ist jetzt genau ein Jahrtausend, daB die Piratennot in dem Ägäischen Meere durch die Eroberung Thessalonikes, der Metropole des damaligen christlichen Orients, ihren Höhepunkt erreichte, ein Ereignis, das die Welt zu erschüttern schien und über dessen Tragweite man in der ersten Bestürzung kein rechtes Urteil abzugeben vermochte. Dies Kapitel der Geschichte Thessalonikes ist so tragisch und ergreifend, daB es der Mühe verlohnt näher darauf einzugehen und die Folge der Ereignisse, so wie sie aus der vorzüglichen Monographie des Johannes Kameniates ${ }^{1}$ ) hervorgehen, in ihrem inneren Zusammenhange mit den Ortsverhältnissen, einer eingehenden Erörterung zu unterziehen. Hierbei soll die Ortskenntnis des Kameniates, der über die Katastrophe als Augenzeuge berichtet, näher gewürdigt und den wesentlichen Angaben der übrigen zwei Thessaloniker Monographen, des Eustathios und J. Anagnostes, gegenübergestellt werden. Es ist ein merkwürdiges Spiel des Zufalls, daB jene drei großen Ereignisse, die die dunkelsten Blätter der Geschichte Thessalonikes bilden, die Eroberungen durch die Sarazenen (904), durch die Normannen (1185) und durch die Türken (1430) sich in Abständen von annähernd je einem viertel Jahrtuusend zugetragen haben. In den drei Fällen haben sich die Eroberer durch furchtbare Barbarei im Brennen, Morden und Plündern schier zu übertreffen gesucht. Die schrecklichen Szenen, die sich hier zugetragen haben, die kriegerischen Unternehmungen, die ihnen vorangingen, und lehrreiche Aufschlüsse über die Zustände der unglücklichen Stadt haben ihre beredten Darsteller in der Person von Thessaloniker Bürgern Kameniates, Eustathios ${ }^{2}$ ) und Anagnostes ${ }^{3}$ ) gefunden, deren Einzeldar-

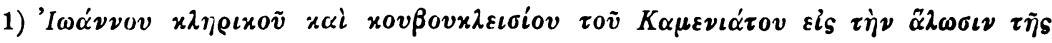
$\Theta \varepsilon \sigma \sigma \alpha \lambda o v i x \eta s$. Ed. Bonn. Script. p. Theophan. p. 487 sq.

2) De capta Thessalonica. Script. p. Leonem Grammaticum. Ed. Bonn. p. 365 sq., bezw. Tafel, Opuscula, Francofurti a. M. p. 267 sq., und Tafel, Komnenen und Normannen, Stuttgart 1870, S. $73 \mathrm{ff}$.

3) De extremo Thessalonicensi excidio. Ed. Bonn. Script. p. G. Phrantzen p. $483 \mathrm{sq}$. 
stellungen zu den lebendigsten Schilderungen der byzantinischen Literatur gehören. Am meisten gewürdigt zu werden verdient die Schrift des Kameniates, die nicht allein inhaltlich, sondern auch sprachlich besonderer Beachtung wert ist. Der unermüdliche Tafel, dessen gröBtes Verdienst ist, die Frühgeschichte Thessalonikes erforscht und aufgehellt zu haben, gab schon in seiner Vorrede zur zweiten Abteilung der „Komnenen und Normannen“1) die Absicht kund, in der ersten Abteilung dieses Werkes eine Abhandlung über „Thessalonichs Eroberungen durch Sarazenen, Normannen und Türken in den Jahren 904, 1185, 1430 “ zu liefern, wohl als eine würdige Fortsetzung seiner Historia Thessalonicae in dem vorzüglichen umfangreichen Werke über Thessalonike ${ }^{2}$ ), in welchem die Topographie der Stadt, die Tafel nie besucht hat, in so treffender Weise behandelt wird. Leider ist jene erste Abteilung der „Komnenen und Normannen“ nicht mehr erschienen; Tafel wurde uns 1860 durch den Tod nur zu früh entrissen. In der vorliegenden Arbeit wird im wesentlichen dieses schon von Tafel angeregte Thema behandelt werden, indem dem Berichte des Kameniates getreu gefolgt werden soll und ein Vergleich mit den späteren Eroberungen durch die Normannen und Türken durch entsprechende Anmerkungen versucht werden wird.

Johannes Kameniates war ein Bürger Thessalonikes $\left.(3)^{3}\right)$, xovßov$x \lambda \varepsilon i \sigma i s_{S}$ der Metropolitankirche dieser Stadt (79). Sein Vater war ebenfalls Geistlicher (55), zwei jüngere Brüder fochten 904 in den Reihen der Verteidiger Thessalonikes gegen die Sarazenen $(42,43)$. Näheres über die Person des Kameniates ist uns nicht überliefert worden. Wir wissen nur, daB die Kameniatessche Familie vermögend genug war, um ihren Mitgliedern das Leben zu erkaufen $(54,55)$. Trotzdem wurde Kameniates mit seinen Angehörigen nach Tarsos in die Gefangenschaft geschleppt und später gegen von den Griechen ausgelieferte Sarazenen ausgewechselt. Von den weiblichen Mitgliedern seiner Verwandtschaft wurden seine eigene Frau mit drei Kindern, seine Mutter, eine jüngere Schwester und seine Schwägerin ebenfalls gefangen genommen (65). Auf der Überfahrt nach Syrien wurde das eine seiner Kinder ein Opfer der Wellen, seine Schwägerin ward in

1) A. a. O. S. XVI.

2) De Thessalonica eiusque agro dissertatio geographica. Berolini 1839. S. III-CIX.

3) Die im Text eingeklammerten Zahlen beziehen sich auf die Kapitelstellen der Kameniatesschen Schrift. In den Anmerkungen beziehen sich die eingeklammerten Zahlen auf die drei angeführten Monographien, und zwar heißt K Kameniates, E Eustathios, A Anagnostes. 
Kreta an Sklavenhändler verkauft (73) und sein Vater starb in Tripolis (78). Den Bericht über die Eroberung Thessalonikes schrieb Kameniates auf Verlangen Gregors von Kappadokien (1), wahrscheinlich in Tarsos, vor seiner Auslösung (79). Die Schrift selbst gehört sprachlich und stilistisch zu den vornehmsten der byzantinischen Literatur. ${ }^{1}$ ) In einem oft sehr anmutigen Redeflub versteht es Kameniates, lurch seine Schilderungen zu fesseln. Dic Kämpfe während der Angriffe der Sarazenen auf die Stadt (23 ff.), die Gräuel nach der Überrumpelung Thessalonikes (36 ff.) und schlieBlich die unsäglichen Leiden und Entbehrungen der Gefangenen auf der Überfahrt nach Syrien (66ff.) boten ihm in ihrem geradezu tragischen Verlauf überreichen Stoff. Aber auch sonst entbehrt der Bericht nicht an reizvollen Stellen, wie die überaus ansprechende Schilderung Thessalonikes und seiner Umgegend ( $5 \mathrm{ff}$.) und vor allem die meisterhafte Darstellung des kirchlichen Gesanges (10). Allein Kameniates ist, so gewandt er auch die Geschehnisse in seiner Gelegenheitsschrift - denn um eine solche handelt es sich nur - niederlegt, kein Schriftsteller von Fach. Während er Einzelheiten von untergeordneter Bedeutung oft weitläufig behandelt, geht er oberflächlich über die historisch gerade belangreichsten Ereignisse hinweg, so daB der umfangreiche, 72 Kapitel umfassende Bericht für die geschichtliche Ausbeute nur wenig befriedigt. Das meiste Interesse verdient aber die Schrift wegen ihrer wertvollen und reichhaltigen Aufschlüsse über die Topographie Thessalonikes und Umgegend (4 ff.). Wir gewinnen aus ihr ein anschauliches Bild von den Verhältnissen, wie sie hier im 10. Jahrhundert vorherrschten, von Handel und Verkehr (6ff.), von den Verteidigungswerken $(4,16 \mathrm{ff} ., 24 \mathrm{ff}$.), den Klöstern und Kirchen $(5,11,39,51)$, dem Klerus (5, 38 f., 43, 51) usw. Aber Kameniates ist zu sehr Kleriker, als daB er den Fall Thessalonikes objektiv darstellen würde. Der Glaube an die erlösende Tätigkeit des Salbenspenders Demetrios $(8,22)$, die Erinnerung an den Apostel Paulus (3), eine kurzsichtige Beurteilung der antiken Welt und des Heidentums $(11,17)$, die häufige Anrufung testamentlicher Stellen $(9,12 \mathrm{ff} ., 22,38,71)$ läBt ihn uns als einen Geistlichen erkennen, wie er für die byzantinische Zeit charakteristisch ist. Seine Kenntnisse von weltlichen Dingen sind beschränkt, was aus seinen geschichtlichen und besonders seinen geographischen Vorstellungen hervorgeht (67 f.). Neben den vielen Vorzïgen, die das Kameniatessche Werk aufzuweisen hat, fällt vor allem die fleißige und sehr sorgfältige Gruppierung

1) Vgl. auch Krumbacher, Geschichte der byzantinischen Literatur, 2. Autl. München 1897, S. 265.

Byzant. \%oitschrift XIV 3 u. 4. 
des Stoffes auf, der, nach dem wirklichen Fortschritt der Ereignisse verständnisvoll gegliedert, uns ein häufiges Nachschlagen, wie es ja bei ähnlichen Berichten oft der Fall ist, erspart. In der sattsam bekannten Weise leitet auch Kameniates seine Erzählung durch die üblichen Ent. schuldigungen und mit der Bitte um Nachsicht ein $(1,2)$, um sie mit ähnlichen Bemerkungen abzuschließen (79). Im übrigen zerfällt das Werk in die folgenden Abschnitte:

( 3-15) Beschreibung von Thessalonike und Umgegend.

(16-22) Vorbereitungen zur Verteidigung.

(23-35) Angriff und Eroberung durch die Sarazenen.

(36-41) Mord- und Plünderungsszenen.

(42-57) Schicksal des Kameniates und seiner Angehörigen.

(58-65) Schicksal der Bevölkerung und Episode des Rhodophilos und Symeon.

(66-78) Verschleppung der Gefangenen nach Kreta und Syrien. $\left.{ }^{1}\right)$

Die Piraten der Kameniatesschen Schrift sind eine überaus interessante Erscheinung des frühen Mittelalters im Ägäischen Meere. Wenn auch über den Ursprung und die frühere Geschichte dieses abenteuerlichen Stammes keine genügende Klarheit herrscht, so läbt sich doch sein historisches Auftreten in den Gebieten des Mittelmeeres schon zu Beginn des 9. Jahrhunderts nachweisen. Die hier auftretenden Sarazenen sind offenbar stammverwandt mit jenen Mohammedanern, die, seinerzeit von Afrika ausbrechend, im Jahre 805 die Stadt Paträ verheerten. ${ }^{2}$ ) Man neigt der Ansicht hin, diese Abenteurer als identisch mit jenen spanischen Arabern zu betrachten, die, aus Cordoba in Andalusien flüchtig, unter einem Emir Abu Hafs Omar I (Ibn Schoeib Ibn Al Galith von Betruh) 814 von Ägypten aus, unter für sie sehr günstigen Vorhältnissen, oinon Boutezug nach den Kykladen unternahmen und sich auf den griechischen Inseln festsetzten. 826 war Kreta von den Sarazenen genommen. Omar setzte sich hier fest, gründete die Stadt Kandak und besiedelte die Insel mit Stammesgenossen. Von diesem Stützpunkte unternahmen die nunmehr als kretische Korsaren bezeichneten Araber ihre häufigen Piratenfahrten nach den übrigen Inseln und den Küsten des Festlandes und waren Jahrzehnte lang der Schrecken

1) In den Werken des Eustathios und Anagnostes über die Ereignisse der Jahre 1185 und 1430 findet sich, mit unwesentlichen Abweichungen, eine ebenfalls sehr sorgfältige Gruppierung des Stoffes vor. Allein es ist uußer Zweifel, $\mathrm{daB}$ in beiden Fällen die Kameniatessche Schrift anregend gewirkt hatte und auch teilweise als Vorlage diente. Eine leise Andeutung hierüber will Tafel im Eustathios c. 81 erkennen (Normannen und Komnenen S. 152, Anm. 314).

2) Const. Porphyrogennetos, De administrando imperio c. 49. 
der auch zu Lande unaufhörlich von fremden Eindringlingen bedrängten Griechen. 829 schlug Omar die griechische Flotte bei Thasos, sein Sohn Schoib I verheerte 866 Prokonnesos, ein sarazenisches Geschwader fuhr 867 sogar bis nach Ragusa und eroberte 878 Sizilien. 881 ward die Westküste des Peloponneses durch die Sarazenen bedroht, aber Oryphas brachte ihnen im Krisäischen Meerbusen, Nasar im Ionischen Meere furchtbare Niederlagen bei, die zur Vernichtung eines Teiles der feindlichen Flotten führten. ${ }^{1}$ ) Schoibs Sohn und Nachfolger, Abu Abdallah, wurde mit seinen Schiffen vom Strategen Konstantinos Sarantapechos abgefangen. All diese Schmach sollte unter Schirkuh, dem nächstfolgenden Emir Kretas, furchtbar gerächt werden; 889 ward Samos genommen, und die Flotte der Piraten nahm drohend den Kurs nach Konstantinopel; 896 fiel die blühende Stadt Demetrias in die Hände der Seeräuber, 900 wurde schlieBlich Lemnos genommen. Die Kreter verfügten über eine mächtige, mit allem Belagerungsgerät wohlausgerüstete Flotte, die mit einem mohammedanischen Mischrolke, Negern, Äthiopiern, Syriern (18) usw., kurzweg Hagarenen genannt (16), bemannt war, ein rohes, blutdürstiges Volk, dessen Fanatismus und Habgier zu einer schrecklichen Waffe wurde. Diese hageren, sehnigen Leute, nur mit einem Lendenschurz bekleidet (35), führten Pfeil und Bogen, ein langes Messer oder Schwert, mit dem sie musterhaft zu fechten verstanden, und als einzigen Schutz einen kleinen Schild (26). Bemerkenswert ist es, daß die Führer der kretischen Piratenflotten zum allergröBten Teile Renegaten waren, die in die Dienste der kretischen Emire traten. So war Photios, der Führer der 881 gegen den Peloponnes ausgesendeten Flotte, ein Renegat, ebenso Damianos, der 896 Demetrias plünderte. Auch Leo von Tripolis, der Held der Thessaloniker Tragödic rom Jahre 904, war ein zum Islum abergetretener Christ (24). Die für die byzantinischen Küsten sich immer bedenklicher gestaltende Lage, die stets drohende Gefahr eines Angriffes der verwegenel Seerïuber auf Konstantinopel bewogen Kaiser Leo VI den Weisen (886-912), eine mächtige Flotte unter Himerios gegen die Kreter in das Ägäische Meer auslaufen zu lassen. Die Bemannung bestand aus nicht weniger denn 28300 Mann, aber die Führung war eine so zaghafte, daB, nachdem 902 ein Angriff auf Kreta selbst mißlang, Himerios den feindlichen Schiffen geschickt auszuweichen verstand und den Korsaren freilieb, neue Piratenfahrten gegen andere Küstenstälte zu unternehmen. Schon zwei Jahre später, 904, fühlte sich Leo von

1) Sümtliche hierauf bezügliche Stellen schlage man bei Muralt, Essai de chronologie byzantine S. $410 \mathrm{ff}$., $462 \mathrm{f}$., nach. 
Tripolis stark genug, um Thessalonike, die große Feste am Thermaischen Meerbusen, mit bedeutenden Kräften anzugreifen.

Thessalonike galt damals als eine der reichsten und wohlhabendsten Städte des byzantinischen Reiches. Begünstigt durch ihre bevorzugte Lage an einem natürlichen Hafenplatze, Ausgangspunkt einer Reihe wichtiger, von der Natur vorgezeichneter Verkehrsadern, hatte sich die Stadt mächtig entwickelt und stand im Glanzpunkt ihrer Blüte. Ein reicher Handel mit den Erzeugnissen des fruchtbaren mazedonischen Bodens, ausgedehnte Handelsbeziehungen mit dem Ausland und den benachbarten slawischen Kolonisten ${ }^{1}$ ) hatten, durch einen lang andanernden Frieden begünstigt, die Bewohnerschaft in ein ÜbermaB der Fülle gestürzt. Neben der fast ausschlieBlich Handel und Gewerbe treibenden Bevölkerung spielte die Geistlichkeit eine grobe Rolle. War doch Thessalonike seit den ersten christlichen Jahrhunderten die Stätte geistlicher Gelehrsamkeit, mehrere Orden hatten sich hier nebeneinander niedergelassen, Klöster waren in der nächsten Umgegend entstanden, die Stadt selbst zierten zahlreiche schöne Kirchen, darunter jene drei großen Hauptkirchen der göttlichen Weisheit (Sophienkirche), der heiligen Mutter Gottes und des heil. Demetrios $\left.{ }^{2}\right)(11)$. Die Kunst hatte sich sowohl an Kirchen, als auch an deren Bilderschmuck und an den städtischen Anlagen in hervorragender Weise

1) Vgl. S. 548 Anm. 2. Kameniates erwähnt noch keine Slawen, die sich dauernd in Thessalonike niedergelassen hatten. Auch die Zahl der Fremden scheint im 10. Jahrh. nicht gerade nennenswert gewesen zu sein, doch bestand auch damals schon eine Kolonie von Ausländern (K 9). Die jüdische Gemeinde in Thessalonike war schon zur Zeit des Apostels Paulus von einer gewissen Bedeutung. Im 12. Jahrh. müssen zahlreiche Handel treibende Lateiner hier ansässig gewesen oin, donn Eustuthion orwähnt ihrer mit aehr gemischten (iefiihlen, da diere 1185 mit den Juden und Armeniern offenkundig zu den Feinden hielten (E 72, 113) und zur Beschleunigung der Eroberung beitrugen.

2) Von den weiteren im 10. Jahrh. in Thessalonike bestehenden Kirchen und Klöstern erwähnt Kameniates nur noch die Georgskirche (51), die Kloster des Apostels Andreas (43) und Akrullion (51) und das von Klöstern bebante Stadtviertel des heil. David (39). Auch im 12. Jahrh. bestanden nach Eustathios immer noch drei Hauptkirchen, die Sophienkirche, die Kirche•der Mutter Gottes (Marienkirche) und jene des heil. Demetrios (Opuscula a. a. O. S. 153), während im 16. Jahrh. schon vier Hauptkirchen bestanden (A 20) die den Griechen von den Türken belassen wurden, obwohl ihnen anfänglich sämtliche Kirchen, mit Ausnahme der Muttergotteskirche und des Klosters des heil. Prodromos, verblieben waren (A 18). Vop den mehr bekannten Gotteshäusern bestanden in Thessalonike noch eine Kirche der Wegführerin Maria [Hodegetria] (E 130), die Kirche des Salbenspenders Nikolaos (E 75), die Kirche der Körperlosen [Asomaton] (E 75), schlieblich das Kloster Chortaition (A 11). Siehe im übrigen hierüber Tafels Thessalonica a. a. 0. S. $107 \mathrm{ff}$. 
beteiligt. Alle diese Vorzüge, die dazu beigetragen hatten, den Ruf Thessalonikes weit über die Grenzen des Landes hinauszutragen, die Aussicht auf reiche Beute, Rache für den in den Vorjahren wiederholt zugefügten Schaden mögen den Sarazenenhäuptling zu einem Raubzug nach dem Thermaischen Meerbusen veranlaBt haben.

In Thessalonike hatte man schon seit langem jede Sorge um die Sicherheit der Stadt fahren lassen. Wohl war der Ort von einer ursprünglich stark angelegten Mauer umgeben, aber man hatte es längst versäumt sie an ihren baufälligen Stellen auszubessern. Im blinden Vertrauen auf den Schutzpatron der Stadt, den heil. Demetrios, welchem alle in den früheren Jahrhunderten glücklich abgeschlagenen Angriffe der Invasionsheere zugeschrieben wurden, hielt man es, mit Blindgeschlagenheit bestraft, für gänzlich überflüssig, die Verteidigungswerke Thessalonikes in brauchbarem Zustand zu erhalten. Hatte doch der heil. Demetrios wahre Wunderdinge für den Schutz Thessalonikes getan. Die Legenden über die seltsame Errettung der Stadt durch den salbenspendenden Heiligen während der verheerenden Züge der Awaren, Slawinen und slawischen Nachbarstämme im sechsten und siebenten Jahrhundert waren in der Erinnerung der Thessaloniker Bürger wach geblieben, und in diesem Vertrauen, das durch keinen Mißerfolg der vergangenen Jahre getrübt war, hatte das Bewußtsein der Unbezwinglichkeit feste Wurzel gefaBt. ${ }^{1}$ ) So kann es denn auch

1) Das Martyrium des heiligen Demetrios hatte fast genau 600 Jahre vor der Eroberung stattgefunden, und zwar am 26. Oktober 303. Demetrios soll, der Legende zufolge, von dem in Thessalonike residierenden Galerius (292-311) hingerichtet worden sein, um einen gewandten Gladiatoren, den Vandalen Lyeus zu rächen, den Nestor, ein Schüler des Demetrios, im Zirkus umgebracht hatte. Der Leichnam wurde von den Freunden les Märtyrers gerettet und innerhalb der Stadtmauern begraben, an derselben Stelle, wo später der Präfekt von Illyrien, Leontios, im 5. Jahrh. einen prïchtigen Tempel über dem Grabe des Verewigten bauen ließ, aus Dankbarkeit für die Heilung von einer gefährlichen Krankbeit unter dem wundertätigen EinfluB des Heiligen. Dieses ist der älteste Nachweis der Wunderwirkungen des Demetrios. Allmählich bildete sich auch aus der dem Heiligen erwiesenen Verehrung ein besonderer Kultus heraus, der selbst außerhalb 'Thessalonikes von großem Kufe war. Bald ward Demetrios Schutzpatron der Stadt, und es wurde ihm die 'Tätigkeit eines unermüdlichen Mitkämpfers und Erretters beigelegt. Insbesondere schrieben ihm d:e Legenden jener Zeit eine erlösende Wirkung während der ununterbrocbenen Reihe von Anstürmen der Ostgoten, Slawinen, Hunnen, Awaren, Skythen, Bulgaren usw. im 6. und 7. Jahrb. zu So hauptsächlich in den Kriegsjahren 597, 600, 675, 677 und 680. - Aber auch nach 904 ist das Vertrauen auf den Heiligen lebendig geblieben. So wirft Demetrios 1040 ein Heer von 40000 Bulgaren vor Thessalonike zurïck. Der heilsame EinfluB des Märtyrers hatte für die damaligen Völker eine ziemliche Bedeutung gewonnen. Schon im 6. Jahrh. ling in der Demetrioskirche 
nicht verwundern, daB nach der furchtbaren Katastrophe vom Jahre 904 selbst ein Mann wie Kameniates das Mißgeschick der Stadt mit unverschleierter Überzeugung der in jenen Jahren herrschenden Sittenlosigkeit und Verderbnis zuschreibt, die den Heiligen bewogen haben konnten, sich von den gottlosen, pflichtvergessenen Bürgern abzuwenden $\left.(12-15,22){ }^{1}\right)$ So entnehmen wir seinen Schilderungen, da $B$ die moralische Verderbnis in Thessalonike eine ungeahnte Ausdehnung erreicht hatte. Die Prostitution, Spitzbüberei, Trunksucht, Zank und Hader hatten groBe Opfer aus der Bürgerschaft gefordert, Habgier und Ehezwistigkeiten führten zu Diebstahl, Mord und Totschlag usw. In einer Stadt, wo, wie in Thessalonike, den Nachrichten zufolge ÜberfluB an Hab und Gut, eine natürliche Folge des zunehmenden Wohlstandes, herrschte und Wohllebigkeit zu einer ïbertriebenen Entfaltung von Luxus führte, sind ähnliche Rückwirkungen auf das sittliche Leben keine seltenen Erscheinungen. Unter diesen Leuten war eben kein kriegerisches, waffenkundiges Element zu suchen, das im gegebenen Augenblick Gut und Blut für die Verteidigung der Stadt eingesetzt hätte.

Sehr bedenklich war es noch, daB auf das räumlich begrenzte Stadtgebiet eine Bevölkerungszahl entfiel, die man als erdrückend bezeichnen muß, wenn sie, der allgemeinen Annahme zufolge, damals wirklich auf 200000 bemessen wurde, was allerdings nicht sehr glaub-

ein Heilbrunnen. Der wundertätige Tempelschlaf wurde hier ein beliebtes und häufiges Heilmittel. Von der gröBten Wirkung soll aber das Öl gewesen sein, das dem Salbenspender beständig aus der Wunde floB und dessen schon auf frühbyzantinischen Inschriften Erwähnung geschieht. 990 pilgerte der Bulgarentöter Basileios II zum Grabe des Heiligen, 1322 wurde Andronikos Paläologos endlich mit dem wundertätigen Öle von einer langjährigen Wunde geheilt, 1185 floB die Wunde des Heiligen in den Tagen gröBter Bedrängnis reicher denn je, aber die Normannen hieben auf das Grab mit Beilen ein und beraubten das Standbild des Heiligen seines silbernen Schmuckes (E 103). 1430 drangen auch die Türken in die Demetrioskirche ein, öffneten das Grab des Märtyrers, beraubten es seines Goldes, Silbers und seiner Edelsteine und schöpften tagelang das heilbringende $O \not l$ hinweg, das auch sie zu wundertätigen $Z$ wecken verwendeten (A 16). Indessen lebt der Glaube an die Wundertätigkeit des Heiligen Demetrios noch heute im Volke fort, und noch heute wird der Demetrios als Salbenspender und Schutzpatron verehrt.

1) Auf ähnliche Ursachen der Verderbnis und Gottlosigkeit führt auch Eustathios (142-147) den Fall Thessalonikes im Jahre 1185 und Anagnostes (3) im Jahre 1430 zurück. Wie man schon $90 \dot{4}$ den Fall der Stadt als eine göttliche Vorsehung betrachtete $(K 14,15)$, 80 erfüllte die Thessaloniker auch 1185 eine böse Vorahnung (E 128, 131), und mit demselben Vurgefühl erwarteten die Bürger 1430 den Angriff der Türken (A 3). Auch ein Erdbeben, das dem Sturme der Türken vorausging, wurde als ein sehr schlechtes Omen für den Ausgang der Belagerung angesehen (A 6). 
würdig erscheint. Ein bedeutender Zuzug der vor Leo von Tripolis flüchtenden Griechen, von den Inseln und der Nachbarschaft, die hinter den Mauern von Thessalonike Schutz zu finden hofften, hatte die Verhältnisse noch bedeutend verschlechtert. ${ }^{1}$ ) Die Besatzung war nur klein; der geradezu unerwartete Angriff der Sarazenen lieB keine Zeit mehr zur Herbeischaffung von genügenden Verstärkungen, deren Bewegungsfreiheit in der überfüllten Stadt ohnedies sehr fraglich erschienen wäre. Kurz, der Fall Thessalonikes war, wenn der Feind es vermochte, einen wuchtigen Sturm gegen die Mauern zu unternehmen, schon aus kriegstechnischen Gründen nicht mehr zu vermeiden. ${ }^{2}$ )

Ehe zur Schilderung der Ereignisse übergęgangen wird, die zur Eroberung Thessalonikes durch die Sarazenen führten, mögen hier zunächst an der Hand eines Planes die fortifikatorischen Verhältnisse der Stadt einige Beleuchtung erfahren, wobei der Verfasser glaubt vorausbemerken zu müssen, daB er sich eine Begründung seiner hier ohne Kommentar gemachten Darlegungen in einer umfangreicheren Sonderarbeit über die Befestigungswerke Thessalonikes vorbehält.

Thessalonike besaB schon in den ersten nachehristlichen Jahrhunderten einen Mauerring, der das Stadtgebiet sowohl von der Wasserals auch von der Landseite vollkommen einschloB. Die in ziemlich

1) Im Jahre 1185 gestattete der damalige Statthalter David einer beträchtlichen Anzahl wohlhabender Leute, Thessalonike gegen entsprechende Geldbeiträge z;u verlassen, um den Normannen zu entgehen; mit ihnen aber entfernte sich auch ein guter Teil der handfesten Arbeiterschaft, der Kern des Volkes, und die brauchbarsten für den Krieg, viele einsichtige und einfluBreiche Leute (E 61).

2) In Jahre 1185 war das Verhältnis ein bei weitem schlechteres. Damals war man auf die Belagerung in keiner Weise vorbereitet. Die Verteidigungswerke waren in Zustande des Verfalls, die Steinwurfmaschinen unbrauchbar, außer der gänzlich versagenden Führung (s.S. 547 Anm.1) mangelte es an dem nötigen Kriegsgerät (E 60), und zum ÜberfluB trat in der Stadt Wassermangel ein. Der hochverräterische Statthalter David hatte es selbst auf guten Rat hin versäumt, die nötigen Vorkehrungen zur Ausbesserung der großen Zisterne auf der Burg zu treffen, so daB das Wasser in den zerstörten Behälter und in Strömen durch die Stadt HoB, bis auch dieser Quell rersiegte (62). - 1430 war Thessalonike unter der Herrschaft der Venezianer, denen es nicht viel um das Wohl der Stadt zu tun war. Ibr merkwürdiges Verwaltungssystem hatte, besonders durch ein strenges Polizeiwesen, eigentümliche Zustände geschaffen. Mit der Unzufried-nheit der Bevölkerung rechnete deshalb Murad und versuchte es, zunächst durch Úberläufer die Griechen zum Verrat zu bewegen (A 6). Aber die Belagerung war 1430 nicht unerwartet erfolgt, da ja die Türkennot hier längst ihren Gipfelpunkt erreicht hatte. Auffälligerweise hatten die Venezianer nur verschwindend wenig unternommen, um dem Angriffe der Türken zu begegnen, und die gereizte Stimmung unter dem Volke hatte hinreichend den Fall der Stadt vorbereitet. 
gerader Linie verlaufenden Mauern der Ost- und Süd(See)seite stießen im rechten Winkel aneinander, während die Nordwestseite eine Wellenlinie bildete, die den Unebenheiten des gebirgigen Geländes folgte und dem Stadtfelde eine im großen und ganzen dreieckige Gestalt verlieh. Der nordöstliche Winkel des Drejecks war durch eine Quermauer in einen kleinen Nordabschnitt, die sog. Akropolis, abgeteilt, an deren nordöstlichstem Ende sich die eigentliche Burg, das Heptapyrgion (heute Jedikule) erhob. Im Südwestwinkel, wo die Mauer bedeutend eingerïckt ist, lag der heute vicht mehr sichtbare, durch Terrainanschüttungen verwischte Hafen, ron ziemlich quadratischer Gestalt, mit einem Wellenbrecher und Hafeneingang (4). Die Mauern, die in ihren verschiedenen noch erhaltenen Abschnitten heute sehr abweichende Bauperioden erkennen lassen, folgen so ziemlich genau den mittelalterlichen Befestigungsfluchten, was schon durch das Gelände bedingt wird, indem die Mauerlinien den tiefeinschneidenden Wildbachrinnen folgen, welch letztere natürliche, unschätzbare Hindernisse bilden und die Anlage von Gräben überflüssig machten. Die auf dem ansteigenden Terrain liegenden Mauerteile waren deshalb infolge ihrer begünstigten natïrlichen Lage schon in ältester Zeit die stärksten. Weniger günstig waren die Verhältnisse auf dem südlicheren, ebenen Geländestreifen, wo etwa je ein Drittel der Ost- und Nordwestmauer auf dem Flachlande der Küste lag. Hier war auch bald die Anlage einer Vormauer notwendig geworden, die selbst bis zur Türkenzeit bestand. Von der Seemauer ist heute nichts mehr erhalten; den Zeugnissen der Schriftsteller zufolge war sie die am wenigsten widerstandsfähige. Sämtliche Mauerteile hatten in ihrer Anlage die üblichen Formen von in kurzen Entfernungen auf Kurtinen folgenden Flankierungstürmen teils quadratischen, teils spitzwinkligen Grundrisses, mit Brustwehren, Zineen und Wallgängen. Größere terrassierte Türne haben von jeher an den bedeutendsten Brechpunkten der Mauern gestanden, sind aber in späteren Jahren durch bessere Bauten ersetzt worden. Überliefert sind nur folgende Turmnamen. An der Südostecke, hart am Meeresufer, der Turm des Chamädrako (12. Jahrh.), später die Seefestung oder Burg Samaria $\left.^{1}\right)$ (14./15. Jahrh.) - jetzt „Weißer Turm“. Am Nordende der östlichen Hauptmauer der "Stadtturm" (12. Jahrh.) - jetzt Kuschakli Kule. An dem dritten Vorsprung der in drei Winkeln ausspringenden Nordwestmauer, Trigonium genannt, der Turm des Manuel (13. Jahrh.). An der Südecke der Nordwestmauer der Ekklesiastische Turm (7. Jahrh.) und am Westende der ans Hafenbassin stoBenden Seemauer der Turm

1) S. S. 550 Anm. 2. 
der Bürger (12. Jahrh.). Neben einer großen Anzahl von kleinen Pforten besaB die Mauer mehrere groBe Haupttore, die dort, wo auch eine Vormauer lag, aus zwei oder mehreren hintereinanderliegenden geschützten Eingängen bestand. In der Ostmauer lag, neben der Burg Samaria, das Römische Tor; nördlicher, an der Hauptstraße, das Kas-

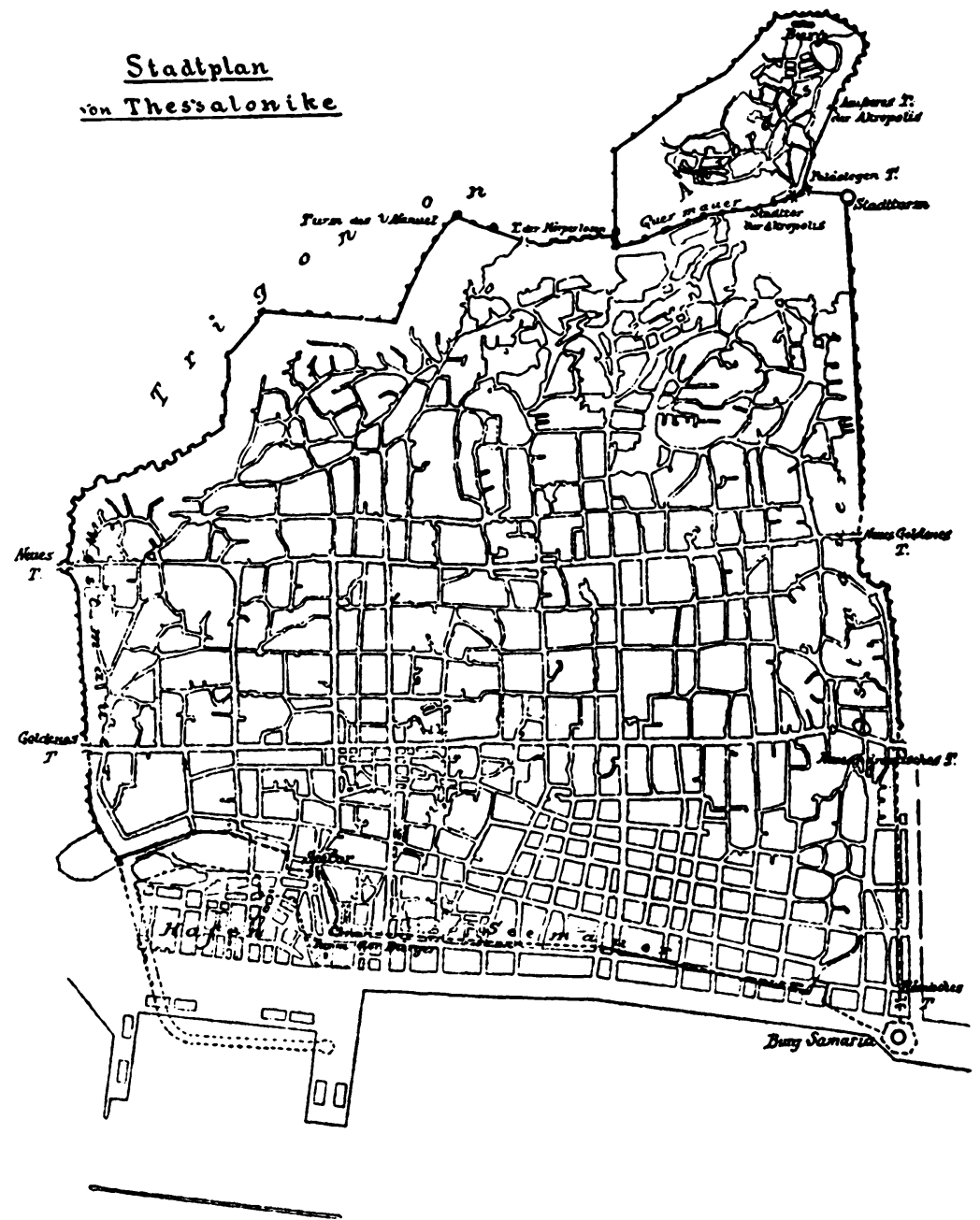

sandreotische Tor (jetzt Kalamaria-Tor), an der zweiten Durchgangsstraße, noch weiter nördlich, das neue Goldene Tor (Telli Kapu). Neben dem Stadtturm, schon im Norden, befand sich das Paläologentor. Vor dem Abschnitt der Akropolis führte an der Ostmauer ein „äußeres Tor" ins Freie, an der Quermauer das "Stadttor der Akropolis" in die untere Stadt. An der Nordwestmauer kennen wir: im nördlichsten 
Teil des Trigoniums das Tor der Körperlosen (das Tor der Verräter, Delik genannt), am Westende der zweiten Durchgangsstrabe das Neue Tor (Jeni Kapu) und an der HauptstraBe das Goldene Tor (Wardar Tor). In das Hafengebiet führte die kleine Ekklesiastische Pforte und das große Seetor. SchlieBlich bestand noch in der Seemauer das Litäische Tor, dessen Lage nicht genau bestimmt werden kann.

Die aus Bruchsteinen und häufigen Ziegellagen aufgebauten Mauern waren ursprünglich vertrauenswürdig genug, um selbst einen zähen Angreifer abzuweisen. Im Jahre 904 war deren Zustand aber, wie schon kurz erwähnt, ein sehr beklagenswerter. Die Ostmauer, die von jeher den Angriffen am meisten ausgesetzt war, galt als sehr schwach, besonders wurde aber über den schlechten Zustand der Seemauer geklagt (16), die ohnedies erst in späterer Zeit entstanden war (8), in der Anlage schon schwach ausgeführt und besonders niedrig war (17), so daB man von den hohen Schiffen, die bis dicht an den Wall herangefahren werden konnten, die Mauer bequem zu ersteigen vermochte. ${ }^{1}$ )

Als Leo von Tripolis im Frühjahr 904 mit seinen Schiffen im Ägäischen Meere kreuzte, befand sich Thessalonike mit seinen Bürgern in einem Zustande der völligen Hilflosigkeit. Kaiser Leo VI hatte ihm wohl eine griechische Flotte unter Himerios, dem wir schon 902 vor Kreta begegnet waren, entgegengeschickt, aber dieser war zu feig und zaghaft, um dem Mohrenhäuptling ein Treffen zu liefern, so wenig man darüber im Zweifel war, daB die Fahrt der Kreter diesmal Thessalonike, der Weltstadt am Nordufer des Ägäischen Meeres, galt, wo kretische Spione die Widerstandsfähigkeit der Befestigungswerke längst ausgekundschaftet hatten. Schon die erste, durch einen Sendboten Kaiser Leos, den Protospatharios Petrouas, gebrachte Nachricht von der Annährung der Piraten, mit der gleiclyzeitigen Aufforderung des

1) Der schlechte Zustand der Mauern bildet den Hauptgrund der Klage auch der späteren Schriftsteller. Dic Seemauer war nach Eustathios schon in der Anlage schlecht gebaut und in einem jämmerlichen Zustand; zum Glück war aber 1185 das Wasser so seicht, daB die Normannen mit ibren Schiffen nicht dicht genug heranfahren konnten (E 59). Die Ostseite blieb der schwächste Punkt der Landbefestigungen auch in den nachfolgenden Kriegen. Desbalb wurden auch 1185 die Teile der Ostmauer mit besonderer Wucht angegriffen, und zwar mit entschiedenem Erfolge (E 83 ff.). Auch Sultan Murad erkannte 1430 die Schwäche der Ostmauern, weshalb er einen Teil seines Heeres diese Mauern stürmen lieB (A $11 \mathrm{ff}$.); damals litt übrigens die Stadtmauer besonders durch ein heftiges Erdbeben in der Nacht vom 26. März ganz erheblich. An eine gründliche Ausbesserung der morschen Manerteile konnte natürlich nicht mehr gedacht werden, und so beschränkte man sich nur darauf, einige Brustwehren aufzumauern (A 5,6$)$. 
Kaisers an die Bevölkerung, sich eiligst zu bewaffnen und zum Kriege zu rüsten, rief Entsetzen und Bestürzung in der Stadt hervor (16). Jetzt erst erkannte man den beklagenswerten Zustand der Wälle und wollte an deren Wiederherstellung schreiten; allein Petronas war umsichtig genug, um einzusehen, daB sich diese Riesenarbeit im Verlaufe weniger Tage oder Wochen unmöglich bewältigen lieB, und entschloB sich zu einem anderen Mittel, um den Angriff von der Seeseite, wenn nicht zu vereiteln, so doch möglichst zu erschweren. $\mathrm{Zu}$ diesem $\mathrm{Zwecke}$ unternahm er die Herstellung eines submarinen Walles in einiger Entfernung von der Seemauer, indem er Steine und Blöcke, zum gröBten Teile griechische Denkmäler aus den antiken Friedhöfen im Osten und Westen der Stadt, ins Meer versenken lieB (17). Diese Arbeit, zu der alle verfügbaren Leute herangezogen wurden, schritt rüstig vorwärts und war ungefähr zur Hälfte beendet, als Leo Chatzilakios, der neuernannte Stratege des Themas Thessalonike, erschien, die Verteidigung der Stadt übernahm und jene mühselige Arbeit, das Werk des Petronas, einstellen lieB, um mit allen Kräften zur Aufmauerung der Seemauer zu schreiten (18). Der häufige Wechsel des Kommandos, der in der Überstürzung von Konstantinopel aus verfügt wurde, sollte den Fall der Stadt nur noch weiter beschleunigen. ${ }^{1}$ ) Kurz vor dem Eintreffen

1) Es muB festgestellt werden, daB Bürger und Besatzung von Thessalonike sich 904 äußerst tapfer hielten und heldenmütig kämpften. Die Eroberung durch die Sarazenen war einerseits durch die wenig einheitliche Führung und andererseits durch den damals eingerissenen Schlendrian in der obersten Leitung, die es verabsüumte, die Verteidigungsmittel in einem zeitgemäBen Zustand zu erhalten, rerschuldet. Nicht unähnliche Verhältnisse lagen aber auch später in den Jahren 1185 und 1430 ror. Zur Zeit der Normannennot verlieB sich Kaiser Andronikos anf den Statthalter Mavid Komnenos, dem er dic Sorge für die Verteidigung Thessalonikes ïberlieB. Allein das Verhalten Darids war ein derart feiges, da $B$ es geradezu an Verrat grenzte. In Thessalonike waren die Verhältnisse nun eben so schlecht, daß die Stadt ohne auswärtige Unterstützung nicht zu halten war, insbesondere waren es die Mauern, die wenig Vertrauen erweckten, und zudem mangelte es an dem notwendigsten Kriegsgerüt. David lieB den Kaiser absichtlich darïber im unklaren, offenbar un nicht zur Verantwortung gezogen und, da er schon in Ungnade stand, geblendet zu werden (E 57). Die Vorstellungen der Bürger blieben fruchtlos, selbst der im letzten Augenblick in Thessalonike eingetroffene Feldherr Maurozomas (S. 549 Anm. 1) vermochte nicht, den Statthalter zu einer entschlossenen Abwehr zu bewegen. Am rühmlichsten tat sich in jenen Schreckenstagen der Krzbischof Eustathios hervor. Ebenfalls rühmlich hervorgehoben zu werden verdient, daB die Bürger 1185 mit an Verzweiflung grenzender 'Tapferkeit gegen den uın vieles üherlegenen Feind kämpften und erst nach der hartnäckigsten Gegenwehr die Mauern räumen muBten ( $E$ bes. 85, 86). - 1430 hatten die Venezianer in Thessalonike so wenig erfreuliche $\mathrm{Zu}$ stände geschaffen, daB von einer entschlossenen Verteidigung der Stadt durch die 
der Piraten kam schlieBlich der vom Kaiser ausschlieBlich für die Verteidigung der Stadt bestimmte Stratege Niketas nach Thessalonike und verwarf seinerseits wieder die Pläne seiner Vorgänger. $\mathrm{Zu}$ allem ÜberfluB endlich wollte noch ein unglücklicher Zufall, daB bei der BegrüBung des neueingetroffenen Platzkommandanten Chatzilakios von seinem scheugewordenen Pferde stürzte und schwer verletzt wurde (19). Niketas übernahm den Befehl und die Leitung der Arbeiten und lieB, da die Aufmauerung des Seewalles nicht rasch genug fortschritt, an den zerstörten Stellen der Mauer Holztürme errichten. ${ }^{1}$ ) Seine Hauptsorge war darauf gerichtet, die verfügbaren Streitkräfte durch aus der Nachbarschaft herbeigezogene Krieger zu verstärken. Er wandte sich deshalb an die in der Umgegend angesiedelten slawischen Stämme, Sagudaten, Dragubiten usw., die in einem Abhängigkeitsverhältnis zu Thessalonike standen und tributpflichtig waren, insbesondere aber an den Häuptling der im Thema Strymon ansässigen Slawen, den er aufforderte, der bedrängten Stadt durch Entsendung von Bogenschützen zu Hilfe zu eilen $(20,6)$. Niketas bestürmte den Strymonier mit Boten und Briefen, aber es war, obwohl der Stratege den Häuptling für alles Unglück, das die Stadt treffen konnte, verantwortlich machte, vergebens. Die Slawen hatten nur'ihren eigenen Vorteil im Auge, und so kamen nur wenige, arme, zum Kampfe nicht sehr fähige Leute, die die Stadt, wie wir später sehen werden, im entscheidenden Augenblick im Stiche ließen. ${ }^{2}$ ) So blieb die Stadt fast lediglich auf eine

geknechteten und gepeinigten Bürger nicht die Rede sein konnte (S. 543 Anm. 2). Zu jener Zeit war Paolo Loredano Duka und Andrea Donato Kapitän in Thessalonike, denen, so tapfer sich die griechischen und renezianischen Krieger verteidigten, keine besondere Widerstandskraft nachgesagt werden kann (s. S. 558 Anm. 8). Thesealonike hätte aich 1420 gewiB lünger halten kñnnen, wenn nicht verräterische Handlungen seitens der Griechen vorgelegen hätten, die zur Beschleunigung der Katastrophe beigetragen hätten (s. S 557 Anm. 1).

1) Auch 1430 halfen sich die Venezianer durch Anbringung ron Holzscbilden zwischen den Zinnen (A 5), um die Krieger gegen die Pfeile der Türken zu schützen.

2) In der Nachbarschaft Thessalonikes bestanden schon seit langem slawische Niederlassungen, die gewiß bis auf die ersten Einfalle der Slawen in Mazedonien im 6. Jahrh. zurückreichen. GröBere Ansiedelungen dieser Art lagen am Strymon, bei Berrhőa und am Pagäischen Meerbusen. Diese slawischen Mischvolker spielten durch das Mittelalter hindurch eine unverkennbar wichtige Rolle, indem sie abwechselnd in Frieden und als Bundesgenossen, dann aber auch als hartnăckige Feinde der Griechen auftraten. Für den Handel von Thessalonike, wo sich die kaufmännischen Juden und Armenier schon seit den ältesten Zeiten niedergelassen hatten, gewann die slawische Nachbarschaft, je mehr diese einer Kultur zugänglich wurde, immer mehr an Bedeutung. Wie 904, so auch 1185 bedienten sich die Belagerten slawischer Bogenschützen - bulgarischer FuB- 
kleine tapfere Besatzung und auf die wenigen kriegskundigen Einwohner angewiesen $(20,21){ }^{1}$ )

Indessen wurde die Nähe des Feindes durch Boten und Flüchtlinge immer häufiger und furchtbarer angekündigt. Anstatt nun wacker Hand an die Verteidigungswerke zu legen, versammelte sich ein erheblicher Teil der geängstigten Bürgerschaft in der Demetrioskirche und rief, der legendarischen Wundertaten des Heiligen in früheren Jahrhunderten gedenkend, ihren Stadtpatron um Schutz und Beistand an (22). ${ }^{2}$ ) Leo von Tripolis war, nachdem er die Anker vor Thasos gelichtet hatte und der griechische Admiral Himerios mit unverzeihlicher Sorglosigkeit vor Lemnos und Samothrake kreuzte, nach dem Thermaischen Meerbusen aufgebrochen.

Am 29. Juli endlich, einem Sonntage, schon beim Morgengrauen, kam die Flotte der Kreter mit geschwellten Segeln bei dem Ekbolos

gänger - und auch Serwier, die gute Dienste leisteten $(E ; 6,106)$. Slawischen Söldnern begegnen wir auch 1430 unter den Verteidigern Thessalonikes, Anagnostes nennt sie Tsetareu (7), jedenfalls ein slawischer Kriegerstamm aus der nächsten Umgegend der Stadt.

1) Nicht viel besser war es 1185 und 1430. Nachdem der Statthalter David vor dem Angriff der Normannen den Abzug zahlreicher Bürger gestattet hatte (s. S. 543 Anm. 1), war die Stadt ihrer hauptsächlichsten Verteidiger entblobt. Zum Glück waren aber die zurückgebliebenen Bürger mutige, kampflustige Leute, die sich mit Entschlossenheit und Begeisterung dem Feinde entgegenstellten. Von dem gleichen Kriegsmute beseelt waren damals die Weiber, die nicht nur Handlangerdienste leisteten, sondern selbst zu den Waffen griffen und an der Seite der Männer kämpften. Auch die Mönche vertauschten das geistliche Gewand mit dem bürgerlichen und sprangen in die Reihen der Verteidiger ( $b$ 69-71). Die Bürgerschaft tat nach Kräften ihre Schuldigkeit und wurde hierbei auf das tapferste von einigen Söldnertruppen unterst.ïtzt. Diese Resatzung erhielt durch das allerdings nur schwache Heer des Johannes Maurozomas, der aus dem Peloponnes nach Thessalonike kam, einige Verstairkungen (E 68). Neben den herangezogenen Bulgaren (s. S. 548 Anm. 2) kümptten auch Alanen und Iberier, die sich durch Tapferkeit auszeichneten (E 69). Weder für das Jalur 904 noch für 1185 wird die Zahl der Verteidiger genannt, sie mochte indessen nicht gerade betrïchtlich gewesen sein. - Unter gewiB weit schlechteren Verhältnissen muBte 1430 Thessalonike gegen die Türken verteidigt werden. Sowohl die Besatzung als auch die kampffähige Stadtbevölkerung war schlecht bewaffnet, außerdem reichte sie kaum aus, um die Brustwehren zu besetzen, denn es entfiel erst auf jede zweite oder dritte Zinne ein Mann (A 5). Die Bürger leisteten einen ver¿weifelten Widerstand, und auch hier sollen sich die Weiber in hervorragender Weise ausgr\%eichnet habeu, indem sie entweder selbst zu den Waffen griffen, oder bei der Herbeischaffung von Gerïtschaften halfen (A 11).

2) Úber die Zusammenkünfte in den Kirchen vor Beginn der Belagerung, Anrufung der Heiligen, insbesondere des Stadtpatrons Demetrios, vergleiche man fïr 1185 E 128-133 und für 1430 A 10. 
genannten Vorgebirge in Sicht. Die Nachricht hiervon rief in der Stadt wieder große Bestürzung hervor (23). Schleunigst wurden die nächsten Anstalten zur Verteidigung getroffen. Die Bürger ergriffen die Waffen und besetzten die Mauern und Tore (22); die slawischen Krieger, immerhin gute Bogenschützen, wurden an der Seemauer aufgestellt, wo der erste Angriff zu gewärtigen war (25)). Der Eingang zum Hafen wurde durch eine eiserne Kette und durch versenkte Schiffe gesperrt $\left.(25)^{1}\right)$, und das einzige zur Verfügung stehende große Geschütz, eine feuerschleudernde Maschine, kam an der östlichen Vormauer, dem schwächsten Teile der Landbefestigungen, zur Aufstellung (41). ${ }^{2}$ ) Von einem günstigen Südwinde getrieben, kam die Flotte bald bis dicht vor den Seemauern heran. Die Segel wurden eingezogen, und nachdem der Korsarenführer Leo die Angriffspunkte längs der Seemauer ausgekundschaftet hatte, ging das Geschwader etwas östlicher vor Anker (23, 24). Die vom Renegaten Leo geführte Flotte bestand aus 54 großen Schiffen $(18,61)$ zu je 200 Mann Besatzung $(67)$, insgesamt 10800 Krieger, ein gemischtes Heer aus Kretern, Arabern, Mohren, Syriern usw. in der einfachen schon kurz erwähnten Ausrïstung. ${ }^{3}$ )

1) Ein ähnliches Beispiel der SchlieBung des Hafens von Thessalonike durch eine Kette und durch Versenkung von Schiffen geht auf das Jahr 675 zurück. 1185 war der Hafen noch in gutem Zustande, doch wurde damals versäumt, irgendwelche Vorkehrung zu treffen, um das Einlaufen von Schiffen hier zu verhindern. - Für 1430 muB gezweifelt werden, ob die ursprüngliche Hafenanlage noch irgendwelchen praktischen Wert hatte; sie dürfte zu jener Zeit bereits gänzlich versandet gewesen sein.

2) An VerteidigungsmaBregeln mangelte es 1185 gänzlich. David befahl nur, die Tore zu schlieBen, und widersetzte sich sogar einem jeden von der Besatzung geforderten Ausfall (E 58) [s. S. 543 Anm. 2]. - Zur Zeit der Türkennot hatte Venedig wohl einige Vorsorge gegen die sicher zu erwartenden Angriffe der Türken getroffen. Schon 1423 waren venezianische Truppen in die Thessaloniker Festung Samaria gelegt worden, es wurden große Rüstungen betrieben und eine Flotte nach Thessalonike entsendet; als aber Murad 1430 vor Thessalonike erschien, erwiesen sich alle Maßnahmen als gänzlich unzulänglich. In aller Eile wurden nur einige Ausbesserungen an der Mauer vorgenommen, Schutzschilde aus Holz hier angebracht (8. S. 548 Anm. 1) und eine venezianische Kanone in Tätigkeit gesetzt (A 9), doch hatte diese letztere nur wenig Wirkung.

3) Die Normannen griffen 1185 Thessalonike gleichzeitig mit einer Land- und einer Seemacht an. Das Landheer zählte 80000 Mann und bestand aus Bogenschützen zu Pferde (5000 Reiter), leichtem FuBvolk und sonstigen Bewaffneten, darunter eine große Anzahl unbesoldeter Freibeuter (E 138) unter Anführung des Grafen Alduin (Balduin) und des Grafen Riccardo di Accera. Bei Dyrrachion an Land gebracht, zog das Landheer durch Epirus und traf am 6. August 1186 vor Thessalonike ein (E 55). Die von Tancred befehligte Flotte zählte 200 Schiffe, die nicht zum geringsten Teile mit Seeräubern, die einen Anteil an der Beute batten, bemannt waren (E 138); darunter befanden gich auch sizilianische Sarazenen (E 123) und 
Ohne lange zu zögern, unternahm der Piratenführer, gleich nach seinem Eintreffen, am ersten Tage, einen Angriff $^{1}$ ) gegen die Seemauer, und zwar an jener durch den unterseeischen Wall nicht behinderten Stelle, wo das Meer an den FuB der Mauer heranreichte. Rudernd wurden die Schiffe dorthin geführt; mit furchtbarem Kriegsgeschrei und unter den dumpfen Tönen der Pauken warfen sich die Sarazenen gegen die dichtbesetzte Seemauer, von welcher ein wohlgezielter Pfeilregen niederging, da hier die slawischen Bogenschützen unschätzbare Dienste leisteten (25). Eine Schar feindlicher Krieger versuchte schwimmend zu der Mauer zu gelangen; mit dem über den Körper gehaltenen Schilde gelangte sie wohl ans Ziel und konnte hier die Leitern anlegen, aber die Leute wurden sämtlich niedergeschossen, so daB sich Leo entschließen muBte abzuziehen und aus der Ferne eine beständiges PfeilschieBen zu unterhalten, dem gegenüber die Bürger mit einigen Petrobolen antworten konnten (26). Die Bürger wie die Feldherren taten ihr Möglichstes, um sich dem Feinde gewachsen zu zeigen. Niketas feuerte die Leute durch zündende Reden an, und selbst der schwer verletzte Chatzilakios durcheilte, anf einem Maulesel reitend, die Reihen der Kämpfenden und sprach den auf den Mauern befindlichen tapfer zu (27). ${ }^{2}$ ) Noch einigemal unternahmen die Kosaren an diesem Tage den Angriff gegen die Seemauer, aber vergebens ${ }^{3}$ ), und mußten deshalb

das Schiff eines berüchtigten Piraten Siphantes (E 93). Die Flotte umschiffte den Peloponnes und traf am 15. August vor Thessalonike ein (E 75). - Uber die Stärke des türkischen Heeres Sultan Murads II im Jahre 1430 läbt uns Anagnostes im unklaren; die vielfach mit der zehnfachen Úberlegenheit des Feindes bezeichnete Größe des türkischen Heeres beruht auf sichtlichen ẗbertreibungen der griechischen Schriftsteller. Murad traf vor Thessalonike am 26. März 1430 ein; er war ebenfalls durch eine, wohl nur aus wenigen Schiffen bestehende Flotte unterstützt, deren Treffen mit drei im Hafen liegenden Galeeren für die Türken unglücklich verlief (A 10).

1) Eine Aufforderung zur Ubergabe der Stadt, wie sie von den Türken im Jahre 1430 an die Bürger erging, erfolgte weder 904 noch 1185. Sultan Murad zögerte in den ersten Tagen mit dem Angriff und versuchte es, die Stadt zunächst ohne Opfer zu gewinnen. $\mathrm{Zu}$ diesem $\mathrm{Zwecke}$ wurden auch Briefe mit der Aufforderung zur Ửergabe wittels Pfeilen in die Stadt geschossen (A y).

2) Man wird anerkennen müssen, daB die Strategen, trotz des bäufigen Wechsels im Kommando, sich gegenseitig tapfer unterstïtzten. 1185 setzte sich der verräterische Statthalter David dem öffentlichen Spotte aus, indem er, anstatt eine Rüstung anzulegen oder ein $\operatorname{RoB}$ zu besteigen, mit weiten Hosen, neumodischen Schuben und mit einer roten iberiscben Mütze angetan, auf einem Maulesel umberstolzierte und sich auBer Schußweite hielt (E 64).

3) $\mathrm{DaB}$ die Normannen die Stadt 1185 von der Seeseite nicht in ähnlicher Weise wie die Sarazenen angriffen, hatte seinen Grund in den inzwischen wohl verschlechterten örtlichen Verhältnissen (8. S. 546 Anm. 1). Es ist aber auch 
zurückgehen, um die Schiffe östlich der Stadt zu verankern. ${ }^{1}$ ) Doch wählten sie eine am Südostende der Stadtmauer, nahe dem Ankerplatz gelegene Stelle, die des Römischen Tores, gegen welches sie bis zum Beginn der Dunkelheit von ihren Bogenschïtzen ein ununterbrochenes PfeilschieBen unterhalten lieBen. In der Nacht herrschte beiderseits Ruhe und ein verschärfter Wachtdienst auf den Wällen (28).

Am Montag, dem 30. Juli, aber, schon in früher Morgenstunde, kamen die Korsaren an Land $^{2}$ ), lieBen zahlreiche Petrobolen aufstellen, davon nicht weniger denn sieben aus Thasos mitgebrachte Maschinen ${ }^{3}$ ) vor dem Römischen Tore und schleuderten damit ungeheuer groBe Steine gegen die Verteidiger; daraufhin unternahmen sie in geschlossener Reihe einen Ansturm auf die Südostecke der Ostmauer. Wieder gelang es einzelnen feindlichen Kriegern so nahe heranzukommen, daB die

nicht ausgeschlossen, daB die Versenkungen vom Jahre 904 noch immer ein nicht zu unterschätzendes Hindernis bildeten. $\mathrm{DaB}$ an dieser Unterlassung nicht etwa ein besserer Zustand der Seemauern schuld war, geht deutlich aus der Eustathischen Beschreibung dieses Mauerteiles (59) hervor. Die Normannen beschränkten sich nur darauf, die Verteidiger während des allgemeinen Sturmes durch eine sehr lebhafte BeschieBung der Seemauer aus den Mastkörben ihrer Schiffe zu beunruhigen, muBten aber die Fahrzeuge vor den Pfeilen der Griechen zurückziehen (E 75, 81).

1) Weil die Einfahrt in den Hafen gesperrt war. An der nămlichen Stelle, im Osten, ankerte auch 118 j die Flotte der Normannen (E 59), um später, nach dem Fall der Stadt, zum Teil auch in den Hafen einzulaufen (E 92).

2) Die Sarazenen lagerten hier gegenüber der Ostmauer, vor den vier östlichen Toren. Obwohl Kameniates nicht von Kämpfen an den übrigen Mauerteilen spricht, erfahren wir doch, daB auch im Westen einige Abteilungen sarazenischer Krieger aufgestellt waren ( $K$ 39), ja daB die Korsaren besonders während der Nachtstunden ringa um die Stadt Beobachtungsposten aufgestellt hatten (K 32). - Im Jahre 1185 bezogen die Normannen zunăchst die Stellungen im Westen der Stadt und umschlossen den ganzen Umkreis bis zur Burg, so daB die Angriffe der ersten Tage dem Mauerteil zwischen dem groben westlichen (Goldenen) Tore bis zur Burg galten (E 55, 56), und gingen erst später zur Ostmauer über (E 75, 8. S. 653 Anm. 3), nachdem sie durch die Mannschaften der Flotte, die sich an dem Kampfe nur wenig beteiligte, verstärkt worden waren. - 1430 bezogen die Türken Stellungen rings um die ganze Mauer, und Sultan Murad schlug ein Zelt auf den Hohen gegenüber der Akropolis auf (A 7).

3) Leo von Tripolis dürfte es übrigens an dem nötigen Sturmzeug gefehlt haben, mit dem die Normannen 1185 reichlich versehen waren. Letztere führten neben leichteren Geschützen auch groBe, plumpe Maschinen (E 59) zum Breschelegen mit sich. Große Dienste leistete den Normannen ein großes Geschütz, Sturmtochter genannt, das Tag und Nacht in Tätigkeit gebalten wurde und mit den damit geschleuderten Felsblöcken die Brustwehren zertrümmerte (E 59, 81). - Die Türken erschienen 1430 ebenfalls mit einem vollständigen Belagerungapark vor Thessalonike, der anf unzähligen Wagen und Kamelen verpackt war (A 8). 
Leitern angelegt, ja einzelne Korsaren sogar zu den Brustwehren der Vormauer hinaufsteigen konnten; aber die Bürger hielten sich tapfer, warfen die Eindringlinge mit dem Speere herab und jagten sie unter allgemeinem Hohngelächter zurück (29). Während die Feinde aus angemessener Entfernung die Griechen beunruhigten, unternahmen sie es, gerade zur Mittagszeit, als die Hitze des Tages am unerträglichsten war, zwei der vier östlichen Tore, das schon genannte Römische und das Kassandreotische Tor, einzuäschern, um in den Zwischenraum der beiden Mauern einzudringen und an die Hauptmauer zu gelangen (30). Sie beluden deshalb kleine Schiebewagen mit Reisig, Pech und Schwefel, was ein ungeheuer lebhaftes Feuer entstehen lieB, und schoben diese Fuhrwerke gegen die erwähnten zwei Tore vor. Die groBe Hitze dieser Scheiterhaufen, die selbst die Eisenbeschläge der Türflügel glühen machte, wäre der Stadt gefährlich geworden, wenn die tapferen Bürger nicht eilends die inneren Türöffnungen ausgemauert hätten, so daB der Feind nach der Einäscherung der eisernen Tore erkannte, daB er überlistet worden war. ${ }^{1}$ ) Wieder zog er sich zurück und beschoB die Stadt bis zum Abend mit den Petrobolen (34). ${ }^{2}$ )

Dem Renegaten war es klar geworden, daB ein jeder Versuch, die Stadt von der Landseite zu nehmen, vergeblich sein muBte ${ }^{3}$; hierzu

1) Ein Beispiel von der Errichtung einer Gegenmauer hinter der durch Untergrabung zum Einsturz gebrachten Hauptmauer findet sich in der fïr die Belagerungstechnik sebr interessanten Schilderung des Eustathios c. 79, 80, 82.

2) Zu einem Angriff auf die Westmauer kam es 904 überhaupt nicht. Die Normannen richteten ibre ersten Angriffe gegen die Westmauer, wurden hier aber zurückgeschlagen (E 75). Auch während des Hauptsturmes wurde 1185 die Westseite berannt, aber wieder ohne Erfolg (E 59). Tapferen Widerstand leistete hier Leo Kutalas mit seinen Leuten, als diu Normannen schon in Thessulonike eingedrungen waren (E 86). - Während des Hauptsturmes im Jahre 1430 führte Sultan Murad einen Teil seines Heeres persönlich gegen die Westmauer, und zwar gegen das sog. Trigonium, an der Stelle des Klosters Chortaition (A 11), und hier gelang es dem Feinde auch, die Mauer zunächst zu ersteigen (s. S. 555 Anm. 1).

3) Hierzu war die ihm zur Verfügung stehende Mannschaft nicht zablreich genug und für den Krieg zu Lande weniger tauglich. - An der Ostseite waren die späteren Eroberungsheere bei weitem glücklicher gewesen. Nach vergeblichen Versuchen, die Westmauer zu erstürmen, gingen die Normannen 1185 gegen die Ostmauer vor, und zwar vom Seestrande bis zu dem an der Nordseite liegenden Tor der Körperlosen, zunächst wohl mit wenig Erfolg (E 75); als aber nach dem Eintreffen der Flotte mit ihrer Unterstützung (s. S. 551 Anm. 3) der allgemeine Sturm unternommer. wurde, richtete er sich gegen diese Seitc. Ein von den Mauern herab unternommener Ausfall der Belagerten änderte nur wenig an der kritischen Lage (E 75). Die Normannen füllten die Gräben aus, rissen die Vormauer nieder und untergruben die Hauptmauer (E 59, 77-79). Von dieser 
schien ihm der Gegner bei weitem überlegen zu sein. Seine eigene Überlegenheit kam nur im Seekriege zur Geltung, und so entschloB er sich, noch einmal gegen die niedrige Seemauer vorzugehen; aber auch diesmal wollte er es versuchen ohne groBen Kraftaufwand durch technische Mittel Herr der Stadt zu werden. Nachdem rings um die Mauer und vor den Toren Wachtposten der Korsaren aufgestellt worden waren, lieB Leo in der Nacht die Anker lichten und traf beim Scheine zahlloser Lichter die Vorbereitung für den nächsttägigen Angriff. Die ganze Nacht wurde dazu verwandt, um die Schiffe zu je zweien an den Längsseiten mit Ketten zusammenzubinden und durch Mastbäume, Bohlen und Taue eine überhöhte Plattform am Schiffsschnabel zu schaffen, die die Seemauer um ein beträchtliches überragte und auf welcher das gesante Angriffsgerät Platz fand (32). Diese Vorbereitungen entgingen den Belagerten nicht. Obwohl die Lage verzweifelt erschien und die meisten den Fall Thessalonikes voraussahen, wollte man es doch nicht unversucht lassen, dem feindlichen Ansturm mit allen verfügbaren eigenen Mitteln entgegenzutreten, da ja an eine Hilfe von außen ohnedies nicht mehr zu denken war. ${ }^{1}$ ) Man schaffte deshalb alsbald in Muschelgefäßen verschiedene Brennstoffe herbei, u. a. Pech, Kienholz und Kalk (33). So wurde bis zum Morgen auf den Angriff der Korsaren gewartet.

Am Dienstag, dem 31. Juli, bei Tagesgrauen, hatten sich die Schiffspaare den Seemauern bedeutend genähert. Wer noch entschlossen war, dem Feinde Widerstand zu leisten, war von allen Teilen der übrigen Manern hierhergeeilt und traf Vorbereitungen zur $\mathrm{Abwehr}$ des furcht-

Seite drangen auch die Normannen am 24. August 1185, nachdem sie beim Turm dos Chamlidrako oino Mauer zum Einsturz gebracht hatten, in die Stadt ein. (Ưber die tapfere Gegenwehr daselbst 8. E. 85, 86.) - Auch die Türken begannen 1430 mit der Untergrabung der Mauern (A 9) und unternahmen mit bedeutenden Streitkräften einen wuchtigen Angriff gegen die Ostmauer, während gleichzeitig auch im Westen gestürmt wurde (A 11).

1) Nachdem der dem Admiral Himerios gegebene Auftrag, die kretische Flotte zurückzuweisen, unausgeführt geblieben war, wäre selbst der Versucb, ein Entsatzheer bei Beginn der Belagerung zusammenzubringen, erfolglos geblieben, da sich die Stadt eben nicht längere Zeit halten konnte. - Günstiger war es 1185, wo Zeit genug gewesen wäre, der Stadt zur Hilfe zu kommen. Kaiser Andronikos hatte auch rechtzeitig ein Ersatzheer abgehen lassen, das ziemlich groB gewesen sein dürfte, da die einzelnen Abteilungen von dem Mitregenten Johannes, Alexios Gidos, Andronikos Paläologos, Manuel Kamytzes, Theodoros Chumnos u. a. befehligt wurden (E 58), aber David, der Statthalter von Thessalonike, hintertrieb die Plăne der Feldherren. Nur Chumnos hatte den wackeren EntschluB gefaBt, sich an der Spitze seiner Abteilung in die Stadt zu werfen, wurde aber von den Normannen zurückgeschlagen (E 66). 
baren Angriffes. Deu Sarazenen gelang es nun, eines ihrer Schiffspaare wieder dort an die Seemauer heranzubringen, wo das Meer den FuB der Befestigungswerke unmittelbar bespülte. Von den erhöhten Plattformen, die sich hoch über den Schutzmitteln der Bürger erhoben, wurde die Seemauer so heftig mit einem Hagel von Pfeilen, großen Steinen und mit Feuerkörpern verschiedener Art überschüttet, daB es trotz einer sehr wackeren Gegenwehr den Thessalonikern nicht mehr möglich war, die Stellungen auf den Wallgängen zu behaupten, und sie in wilder Flucht nach dem Innern der Stadt auseinanderstoben. Von ihren so plötzlichen und schnellen Erfolgen überrascht, sprangen nun die Sarazenen, mit dem bloßen Schwerte in der Hand, auf die Zinnen und drangen, erst noch zögernd, in die Stadt, ohne auf weiteren Widerstand zu stoBen. ${ }^{1}$ ) Um die dritte Tagesstunde waren die Sarazenen Herr der blühenden Stadt geworden. ${ }^{2}$ ) Von den der Reihe nach anlegenden Schiffen stiegen die Barbaren in die Stadt herab. Die Tore wurden geöffnet ${ }^{3}$ ), und auch die übrigen Sarazenen drangen unaufhaltsam ein, alles, was sich ihnen entgegenstellte erbarmungslos niedermachend. Die Nachricht von dem Eindringen der Barbaren hatte in der Stadt eine grenzenlose Verwirrung verursacht. In einer der Beschreibung spottenden Bestürzung stob alles auseinander und suchte jammernd und wehklagend teils durch Selbstmord, teils durch Zuflucht, wo nur immer möglich, den wilden Eindringlingen zu entgehen. ${ }^{*}$ )

1) Kameniates erzählt (34), daB zunächst ein tollkühner Araber von furchtbarem Anblick die Brustwehren erstieg und daB vor ihm alles entsetzt auseinandersto.b. - Auch 1185 hatte zunächst e in Matrose der Normannen die Mauer glücklich erstiegen, dem, nachdem er seine Kameraden herbeigerufen hatte, die übrigen nachfolgten (E 82-86). - Merkwürdigerweise wird auch für 1430 des ersten Türken mit Schaudern gedacht, der, das Schwert zwischen den Zuhuen haltend, die Brustwehr erklomm und den Widerstand der entsetzt fliehenden Belagerten mit einem Schlage brach (A 13).

2) Die Belagerung hatte 904 nur einen Tag gedauert, vom 29. bis zum 30. Juli. - 1185 dauerte sie vom 6. bis zum 24. August, volle 18 Tage (E 87). 1430 dagegen dauerte sie nur drei Tage, vom 26. bis 29. März. In den drei Fällen erfolgte die Einnahme in den frühen Morgenstunden, 904 und 1430 übereinstimmend in der dritten Tagesstunde ( $\mathrm{K} 34, \mathrm{~A} 12$ ).

3) Der verräterische David hatte 1185 schon in der Frühe des Eroberungstages das östliche (Kassandreotische) Tor öffnen lassen, so daß die Normannen nach der ersten UUberstürzung der Belagerten ohne Schwertstreich in die Stadt eindringen konnten (E 85).

4) Auch als die Normannen 1185 in Thessalonike eindrangen, war die Bestïryung eine üheraus groBe. Alles floh in vilder Verzwaiflung, voran der Statthalter David, zunächst nach der Akropolis, an deren Tor das Gedränge so groB war, $\mathrm{da} B$ die Leute erdrückt wurden und einen ungeheuren Leichenhügel bildeten (E 4, 5, 85). An der Burg selbst wurden viele durch das Niederlassen eines Fall- 
Kameniates schildert mit ergreifenden Worten die Szenen wilder Verzweiflung und der unerhörten Verwirrung, die sich in den ersten Stunden nach dem Eindringen der Korsaren in den Straßen zutrugen. Während man in der ersten Überstürzung Zuflucht in den Kirchen suchte $^{1}$ ) oder durch die Tore ins Freie zu gelangen trachtete, fielen die Sarazenen über die kläglich um Gnade flehenden Bürger her. Doch auch jene, denen es gelungen war, aus der Stadt zu entkommen, fielen in die Hände der Barbaren (37). Jungfrauen und Weiber mit ihren Kindern, ihre Schamhaftigkeit vergessend, liefen mit aufgelöstem Haar weinend auf dem Markt umher. Die Mönche, Einsiedler und Nonnen verließen die Klöster und zogen wehklagend herum (38). ${ }^{2}$ ) Die Sarazenen verbreiteten sich truppweise durch die Stadt und richteten ein furchtbares Blutbad unter den Thessaloniker Bürgern ohne Unterschied des Alters und Geschlechts an. In ihrer grenzenlosen Blutgier wurde niemand verschont. Der grausame Vandalismus, mit welchem die Korsaren hausten, geht schon aus der mutwilligen Verstümmelung der unglücklichen Opfer hervor, denen zunächst die unteren Extremitäten zerschmettert wurden. ${ }^{3}$ ) Auch in dem Klosterviertel des heil. David, auf der Anhöhe der Stadt, und in der Akropolis breiteten sich die

tores getötet (E 6-8). Viele nahmen sich das Leben, indem sie sich von den Dächern herabstürzten oder in die Brunnen sprangen (E 104), um nicht in die Hände des Feindes zu fallen. - Die Verwirrung bei dem Einbruch der Türken war 1430 unbeschreiblich, alles suchte sich ror den wilden Eindringlingen zu verstecken, wobei die meisten ihnen gerade in die Hände fielen (A 14).

1) Die Kirchen bildeten auch 1185 den Zufluchtsort sehr zahlreicher Leute, die aber hier einen qualvollen Erstickungstod fanden (E 103). Die Gassen füllten sich mit Toten jeden Alters und Geschlechts (E 98). Die mit geweihten Gewăndern versebenen Geistlichen wurdon hingomordet und dio Nonnon goschändot (E 99). Wie auch 904, so spielte in den Jahren 1185 und 1430 bei den gräBlichen Mordszenen der religiöse Fanatismus eine Hauptrolle.

2) Ähnlich wie 1185, wo die Weiber sich sogar von ihren Kindern trennten (E 105). Die einzelnen von Eustathios geschilderten Szenen übertreffen indessen alles andere von den übrigen Eroberern Geleistete. Die Frauen wurden nackt herumgetrieben, Huren erhielten Kirchengewänder, die Männer muBten, notdürftig bekleidet, nachdem sie sich nach fränkischer Art Kinn und Kopf hatten scheeren lassen, die Hauser verlassen, wo die Eroberer einzogen und in der Nacht mit den gezüchtigten Mädchen und Frauen Orgien aufführten. Weder Laie noch Priester war an der Kleidung erkenntlich (E 108-113, 117-119, 123). Auch Anagnostes stellt ähnliche Parallelen; man vergleiche besonders die als groBe Schmach angesehene Zusammenführung von Mönchen mit Frauen, von Mädchen mit Männern usw. (A 14).

3) Der furchtbare Vandalismus, der jenes Blutbad vom Jahre 904 kennzeichnet, steht auf gleicher Stufe mit den ähnlichen Massenmorden in den späteren Kriegsjahren (E $98 \mathrm{ff}$., A 14 f.). 
Feinde aus. Dann zogen sie zu den westlichen Toren, die gesprengt wurden, um auch die hier draußen lagernden Genossen einzulassen (39). Sehr zahlreiche Bürger hatten bei den Toren Schutz gesucht, wo sie sich eng aneinandergepreBt zwischen den zwei Mauern zu verbergen suchten. Hier wütete der Eroberer ebenso erbarmungslos. Beim Goldenen Tor wurde das Volk buchstäblich niedergesäbelt, die Glieder rom Rumpfe gehauen (40). Ebenso erging es denen, die nach dem Seetor Litäa geflüchtet waren. Einige suchten ihr Heil bei der Feuermaschine, die bei einem Tor der östlichen Vormauer aufgestellt worden war. Nur wenige, die im Westen des Hafens zu entkommen vermochten, konnten sich retten; andere entgingen dem traurigen Schicksal ihrer Mitbürger nur dadurch, daB sie noch vor dem Eindringen des Feindes durch das äußere Tor der Akropolis entflohen. Unter diesen letzteren befanden sich die Führer der Slawen, die sich rechtzeitig der Schlüssel jenes Tores bemächtigt hatten, unter dem Vorwande, Verstärkungen von slawischen Verbündeten herbeizuschaffen (41). ${ }^{1}$ )

Kameniates hatte auch versucht, sich mit seinem Vater, zwei jüngeren Brüdern und einem näheren Verwandten vor dem Feinde zu verbergen. Sie flïchteten deshalb in einen baufälligen Turm der Mauer $^{2}$ ), gegenüber dem Kloster des Apostels Andreas, wo sie aber bald von einigen Arabern aufgespürt wurden. Durch Geschenke an diese letzteren entgingen sie dem Tode und stellten den Barbaren gröBere Belohnungen in Aussicht gegen Zusicherung ihres Lebens (42-48). Von mehreren Arabern eskortiert, muBten sie den Turm rerlassen und auf Umwegen, über Haufen von Leichen schreitend, dem Strande zueilen, um vor dem Anführer zu erscheinen. Auf dem Wege wurde Kameniates zweimal von anderen Arabern verwundet $(49,50)$.

1) Man ist vielfach geneigt - aber zu lnrecht -, dieses Verhalten der Sliwen als offenkundigen Verrat zu kennzeichnen. - Eine verräterische Handlung scheint dagegen 1185 vorgelegen zu haben, indem ein gewisser Theophanes I'robatus, der von Dyrrbachion her mit den Normannen nach Thessalonike gezogen war, sich einige Tage vor der Eroberung in die Stadt einschlich und mit dem Feinde enge Beziehungen unterhielt (E 74). Eustathios erwähnt übrigens atuch andere Anzeichen, die auf den Verrat durch einige fremde Kaufleute, durch Juden und Armenier schlieBen lassen (E 72-74, s. S. 540 Anm. 1). - Mit ziemlicher Sicherheit lag inclessen 1430 Verrat vor, der den Fall der Stadt, schon nach einem einzigen Sturme, erklärt. Offenbar war es ein Teil der griechischen (ieistlichkeit, die der lateinischen überaus feindlich gesinnt war und den Türken die Eroberung um vicles erleichterte.

2) Diese Schilderung des Kameniates hätte für die Topographie gröBeres Interesse, wenn sie um einiges deutlicher wäre. Leider läßt sich aus ihr ein genaues Bild von den Lageverhältnissen der Mauerteile und des in Frage stehenden Turmes nicht machen. 
Sie gelangten so zum Nonnenkloster Akrullion und nach der Kirche des heil. Georg. In den Propyläen saB hier ein Chef der Korsaren mit unterschlagenen Beinen, das bloBe Schwert in der Rechten, und verbürgte, nachdem er von dem Vorgefallenen unterrichtet worden war, der Kameniatischen Familie das Leben. Erst nachdem die Barbaren in der Georgskirche, wo etwa 300 Griechen eingesperrt waren, ein entsetzliches Blutbad angerichtet hatten ${ }^{1}$ ), dem der Chef, auf dem Altare sitzend, mit Wohlgefallen beiwohnte, wurde Kameniates mit seinen Leuten nach dem Hafen gebracht und vor den Renegaten Leo geführt (52-53). Kameniates gab nun hier den Ort an, wo der Familienschatz lag, und erkaufte sich und seinen Angehörigen durch Überlassung dieses ganzen Vermögens das nackte Leben, aber nicht die Freiheit, denn Leo eröffnete ihnen, daß sie als Gefangene nach Syrien und nach Tarsos in Kilikien gebracht werden würden, um später gegen von den Griechen gefangen gehaltene Kreter ausgetauscht zu werden $(54,55)$.

Die gräBlichen Mordszenen ließen nach der ersten Blutgier allmählich nach, aber ein erheblicher Teil der Bevölkerung war bereits niedergemetzelt worden. ${ }^{2}$ ) In den Straßen lagen die Leichen der erschlagenen Bürger jeden Alters und Geschlechts herum, Ströme des Blutes flossen über das Pflaster, und dazwischen wurden Fluten des köstlichen Weines ausgegossen (54). Was noch am Leben war, wurde unter Mißhandlungen zum Ufer getrieben, geschlagen und gepeinigt und zu Gefangenen gemacht. ${ }^{3}$ ) Unter ihnen befand sich auch der

1) Was gegen den Geist der damaligen Zeit am meisten verstieB, war die frevelhafte Schänảung der Kirchen. - 1185 richteten auch die Normannen schreckliche Blutbäder in den Kirchen an. Sie zertrümmerten die heiligen Bilder, raubten die Kirchengeräte, entweihten die Altäre in barbarischer, roher Weise, zerschlugen die heiligen Lampen und verhöhnten den Kirchengesang und Gottesdienst ( $E$ 99-102, 121). - Auch 1430 blieben weder Kirchen noch Klöster verschont. Selbst die Gräber wurden geoffnet. Die heiligen Bilder und die kostbaren KirchengefäBe kamen zum Verkauf gleich auf den Markt (A 15). - Über die Schändung der Demetrioskirche in den Jahren 1185 und 1430 vgl. S. 541 Anm. 1. Anagnostes berichtet auch von der Schändung des Grabes der hl. Theodora (A 16).

2) Das Blutbad der Normannen dauerte 1185 nur von der Frühe bis zum Nachmittag und wurde auf Befehl Graf Balduins abgebrochen (E 108), hatte aber 7000 Menschen das Leben gekostet (E 106). Nähere Angaben für 904 und 1430 fehlen.

3) Statthalter David lieferte sich 1185 den Normannen selbst aus (E 8), ob aber Gefangene gemacht wurden, wissen wir nicht mit Bestinmtheit; denn wenn auch Eustathios und Maurozomas anfänglich mit anderen Griechen auf das Schiff des Seerăubers Siphantes geführt wurden, so geschah dies wohl nur in der Absicht, ein entsprechendes Lösegeld herauszuschlagen (E 91-95). - 1430 konnten 
Stratege Niketas und Leo Chatzilakios (56). Zu den Qualen verschiedener Art, welchen die unglücklichen Bürger in ihrer trostlosen Lage preisgegeben waren, gesellte sich der Hunger und Durst. ${ }^{1}$ ) Viele siechten dahin, und jene Verwundeten, die in die Gefangenschaft geraten waren, wurden von den Barbaren getötet, um nicht auf die Schiffe geführt zu werden (57). Bald überwog die Habsucht die Mordsucht der Korsaren. Leo stellte es den Gefangenen frei, sich durch Geld und Kostbarkeiten loszukaufen, und während voller zehn Tage währte die Jagd nach Gold, das man sich wie und wo nur immer zu beschaffen suchte (58). ${ }^{2}$ ) Aber nicht groß war die Zahl jener, die die habgierigen Sarazenen vollauf befriedigen konnten. Am meisten erregte die Wut des unerbittlichen Piratenführers die Pflichttreue des ebenfalls in seine Hände geratenen kaiserlichen Eunuchen Rhodophilos. Dieser hatte vom Kaiser den Auftrag erhalten, eine Summe Geldes von zwei Goldtalenten nach Sizilien zur Kriegskasse überzuführen. Als aber die Flotte der Sarazenen nach dem Thermaischen Meerbusen steuerte, lieB er jene Gelder beim strymonischen Strategen Symeon zurück und gelangte noch kurz vor der Katastrophe nach Thessalonike. Leo, der von dem treuen Beamten nicht erfahren konnte, wo das Geld niedergelegt worden war, lieb ihn in elender Weise martern und töten (59) und drohte die Stadt vollends zu zerstören. Schon hatte Leo an mehreren Stellen, mitten in der Stadt und in dem Viertel am Meere, den Brand in die Häuser legen lassen, als es Symeon nach kurzen Verhandlungen gelang, durch die Auslieferung jener zwei Goldtalente Thessalonike vor der sicheren Vernichtung $\mathrm{zu}$ retten $(63-64){ }^{3}$ )

sich von der Bürgerschaft nur wenige rechtzeitig retten. Paolo Loredano und Andrea Duka suchten nach dem Eindringen der Türken zunächst in der Burg Samaria Zuflucht, sprangen aber dann in die lialeeren und enttlohen (A 13).

1) Dieselben Qualen, über welche Eustathios für das Kriegsjahr 1185 klagt. Er war es übrigens selbst, der durch seine wohlwollende, warme Fürsprache dazu beitrug, das Los der Bürger, solange die Normannen in Thessalonike blieben, zu verbessern.

2) Den Blutdurst überwog auch 1185 die Habgier, wobei die Normannen ron ihren sarazenischen Söldnern tapfer unterstützt wurden. Die Plünderung wurde systematisch betrieben, nachdem die Häuser unter den Kriegern verteilt worden waren. Die Bürger muBten, ebenso wie 904, unter grausamen Folterungen ihr gesamtes Gut hergeben usw. (E 120-126). Kein Gebäude blieb verschont, selbst das kirchliche Hospital wurde furchthar heimgesucht und die Bibliotheken in barbarischer Weise geplündert $(E$ 134, 135). - 1430 wiederholten sich dieselben Szenen auf der Suche nach verborgenen Schätzen, wobei die Türken es verstanden, die Frauen durch falsche Versprechungen zur Angabe der Fundorte zu verleiten (A 15).

3) DaB Leo ron 'Tripolis von Verheerungen in der Stadt Abstand nahm, kann 
Inzwischen ließ Leo die Vorbereitungen zur Abreise treffen. ${ }^{1}$ ) Zur Aufnahme der in die Sklaverei fortzuschleppenden Gefangenen genügten die 54 Schiffe der sarazenischen Flotte nicht, weshalb auch alle in der Reede und im Hafen befindlichen Kauffahrteischiffe der Griechen gekapert wurden, ja selbst die am Eingange zum Hafen versenkten Schiffe wurden gehoben, wieder flott gemacht und mit geraubten Schätzen und Gefangenen angefüllt. Es waren zum gröBten Teile junge Leute, die Blüte der Bevölkerung, über deren Los der Tyrann entschied. $\left.{ }^{2}\right)$ Männer und Weiber wurden gesondert, jeder nur mit dem Allernotwendigsten ausgerüstet, in den Schiffen untergebracht. Was für den Verkauf auf den Sklavenmärkten untauglich war, durfte zurïckbleiben. Die widerstandsfähigsten, kräftigsten Männer wurden den Kapitänen von fünf Schiffen überwiesen, um nach Tarsos übergeführt zu werden $(60-62)$. Kameniates wurde mit einigen Verwandten auf einem ägyptischen Schiff untergebracht, wo, außer 200 Sarazenen, nicht weniger denn 800 Gefangene zusammengeführt worden waren. Endlich, am zehnten Tage nach der Eroberung (10. August), wurden die Anker gelichtet, und die überfüllten Fahrzeuge verließen, nach Süden steuernd, den Hafen $(65-67) .^{3}$ ) Um der im Ägäischen Meere kreuzenden grienicht verwundern, da die Korsaren lediglich auf große Beute ausgingen. - Einen gewissen Ausgleich für den durch die Eroberer zugefügten Schaden suchte 1185 Graf Balduin dadurch zu bewirken, daB er die Ordnung der Dinge wiederherstellte, Recht für Sieger und Besiegte sprach und sein Wohlwollen durch Zuwendung kostbarer Geschenke den geplünderten Kirchen, insbesondere dem übel zugerichteten Grabe des bl. Demetrios bekundete (E 115, 116). - Sultan Murad hatte bei der Eroberıng nur die Stadt mit ihren leeren Häusern für sich in Anspruch genommen (A 17). Nach der Eroberung veranlaBte er die flüchtigen Bürger, nach Thessalonike zurückzukehren, lieB die zerstörten Stadtviertel wieder aufbauen, gab die Häuser den Bürgern wieder zurück, ebenso die Klöster und Kirchen (s. S. 340 Anm. 2). 1432 aber annektierte Murad das gesamte Gut der Bürger einschlieBlich der Häuser, Kirchen und Klöster, und nur vier Kirchen verblieben den Christen (A 19-22).

1) Kameniates versäumte es, nähere Angaben über die Verluste der Sarazenen zu machen. - Die Normannen büBten 1185 etwa 6000 Menschen ein, die Hălfte davon war durch Seuchen hinweggerafft worden (E 137). - Auch über die türkischen Verluste vom Jahre 1430 erfahren wir durch Anagnostes nichts Naheres.

2) Der Feldzug der Normannen hatte 1185 einen politischen Beweggrund, weshalb über das Schicksal der überlebenden Bevölkerung zu ihren Ungunsten nicht entschieden wurde. - 1430 hatte Sultan Murad die Stadt dem Heere zur Plünderung preisgegeben und zugesagt, daB nicht allein die Gold- und Silberschătze, sondern auch die Einwohnerschaft, Männer, Frauen und Kinder, ihnen gehören sollten. Alles, was noch preiswürdig erschien, wurde deshalb $1430 \mathrm{zu}$ Sklaven gemacht (A 14).

3) Die Normannen lieBen sich 1185 genügend Zeit vor dem Aufbruch. Erst im September zog, nachdem eine Abteilung in Thessalonike zurückgeblieben war 
chischen Flotte auszuweichen, segelten die Sarazenen auf großen Umwegen längs der Küste von Euböa nach Andros, Patmos, Naxos und trafen schlieblich (wohl am 26. August, einem Sonntage), vor Kreta ein. Auf dieser Kreuzerfahrt hatten die unglücklichen Thessaloniker unter den mannigfaltigsten Entbehrungen vielfach zu leiden. Mangel an Nahrung und Wasser, Krankheiten, die an Bord ausbrachen, die MiBhandlungen durch die Barbaren u. a. m. sollten die Leiden der hoffnungslosen Bürger vermehren. Viele gingen auf der Überfahrt elend zugrunde und wurden von den Sarazenen ins Meer geworfen. Bei der Ankunft in Zontarion auf Kreta (26. August) wurde das Los der Gefangenen um nichts verbessert (67-71). Sie wurden hier an Land gebracht, gezählt und mit der Beute unter den einzelnen Führern verteilt. Es waren über 22000 Menschen $^{1}$ ) im blühenden Alter, wobei einige besonders gehütete Gefangene, ältere Leute und die auf der Reise umgekommenen Bürger nicht mitgezählt waren. Ein Teil der Gefangenen wurde schon hier, auf Kreta, in die Sklaverei verkauft (72-73). Nach einem Aufenthalt von 12 Tagen ging es weiter (7. September). Ein furchtbarer Sturm, der kurz nach der Abfahrt ausbrach, zertrümmerte eines der Schiffe in der Nähe der Insel Dia, wobei über tausend Menschen ertranken (74-76). Nach fünftägiger Fahrt wurde Paphos auf der Inseln Cypern angelaufen (12. September). Endlich, an 14. September, dem Festtage der Kreuzerhöhung, traf Leo mit seiner reichbeladenen Flotte vor seiner, Heimatstadt, Tripolis in Syrien, ein (77).

Von hier wurden die Gefangenen nach allen Weltrichtungen verschleppt. ${ }^{2}$ ) Die meisten wurden auf dem mohammedanischen Sklavenmarkt von Damaskus gegen hohe Preise losgeschlagen und nach Afrika, Ägypten, selhst bis nach Arabien gebracht. Nur ein geringer Teil der Bürger, zu denen auch Kameniates und seine noch lebenden Angehörigen zählten, kamen nach Tarsos in Kilikien, um später gegen gefangene Sarazenen ausgetauscht oder durch Freundeshand ausgelöst zu werden (78).

und eine zwrite nach Amphipolis und Seres ging, das Hauptheer gegen Konstantinopel, wohin auch die Flotte segelte. - Das türkische Heer zog 1430 fast uninittelbar nach der Eroberung nach Janina.

1) 1430 wurden von den Türken 7000 Menschen zu Sklaven gemacht (A 14). Allein Murad kaufte die angesehensten Bürger von seinen Soldaten wieder los und lieB sie in Thessalonike zurück (A 17). Mit den zurückgekehrten Flüchtlingen scheinen dies etwa 1000 Mann gewesen zu sein (A 19).

2) 1430 wurden die meisten zu Sklaven gemachten Thessaloniker nach Kleinasien verschleppt; viele konnten sich allerdings die Freiheit noch orkaufen, ein Teil von ihnen wurde aber erst später durch Freundeshand ausgelöst (A 17, 19). 
So weit das Wesentliche ans Kameniates' Bericht.

Leo von Tripolis konnte noch 20 Jahre hindurch in unbeschränkter Weise im Ägäischen Meere hausen. Ein erneuerter Versuch der Griechen, die Macht der Sarazenen zu brechen, endete sehr unglücklich für das Kaiserreich. Leo von Tripolis und Damian von Tyros brachten der griechischen Flotte des Himerios bei Samos eine empfindliche Niederlage bei. Erst im Jahre 924 wurde das Schicksal der sarazenischen Piraten durch die gänzliche Vernichtung ihrer Flotte in einer Seeschlacht vor Lemnos entschieden und Rache für Thessalonike genommen. ${ }^{1}$ ) Nur Leo selbst war es gelungen, sich mit seinem Schiffe zu retten; aber dem gefürchteten Renegaten begegnen wir nicht wieder während der letzten schüchternen Versuche der Emire von Kreta, ihre Herrschaft zur See wiederzugewinnen. Durch die Wiedereroberung Kretas durch die Griechen und die Erstürmung von Chandax (Temenos), am 7. Mai 961, ward der kretische Piratenstaat der mohammedanischen Emire endgültig gestürzt.

Salonik, im September 1904.

Adolf Struck.

1) Die Vergeltung für Thessalonike folgte 1185 der Eroberung fast unmittelbar nach. Schon am 7. November wurden die Normannen bei Demetritza durch das griechische Heer unter Alexios Branas völlig geschlagen. 4000 Normannen, Balduin, Richard und der Prätendent Alexios wurden gefangen genommen. In Thessalonike wiederholten sich dann die blutigen Szenen vom August, indem aber jetzt umgekehrt die Griechen über die Fliehenden herfielen und furchtbare Rache für die ihnen zugefügte Schmach nahmen (Nicetas, Is. Angelos I, c. 2). 